\title{
Switching from adalimumab to tofacitinib in the treatment of patients with rheumatoid arthritis
}

Mark C. Genovese ${ }^{1}$, Ronald F. van Vollenhoven², Bethanie Wilkinson³ ${ }^{3}$ Lisy Wang ${ }^{3}$, Samuel H. Zwillich3, David Gruben ${ }^{3}$, Pinaki Biswas ${ }^{4}$, Richard Riese ${ }^{3}$, Liza Takiya ${ }^{4 *}$ and Thomas V. Jones ${ }^{4}$

\begin{abstract}
Background: Tofacitinib is an oral Janus kinase inhibitor for the treatment of rheumatoid arthritis (RA). The aim of this study was to explore the safety and efficacy of open-label tofacitinib following blinded treatment with adalimumab or tofacitinib for moderate to severe RA.

Methods: Analyses included patients treated with adalimumab $40 \mathrm{mg}$ once every 2 weeks or tofacitinib $10 \mathrm{mg}$ twice daily (BID) with background methotrexate (MTX) in a 12-month randomized study (NCT00853385), who subsequently received tofacitinib 10 mg BID (with/without background MTX) in an open-label extension (NCT00413699). Patients with treatment-related serious adverse events (AEs) and serious or recurrent infections in the index study were excluded from the extension study. Exposure-adjusted incidence rates of safety-related events were assessed in 3-month and 12-month periods in the year before and in the year after switching. Efficacy was assessed 3 months before, at the time of, and 3 months after switching.

Results: There were 233 (107 adalimumab to tofacitinib 10 mg BID, 126 blinded to open-label tofacitinib 10 mg BID) patients included in these analyses. Patients in both treatment sequences had similar incidence rates (per 100 patient-years) of discontinuation due to AEs, serious AEs, and serious infections in the year before and in the year after switching. Incidence rates of AEs were increased in the first 3 months after switching compared with the last 3 months before switching in both treatment groups. Switching from either blinded adalimumab or tofacitinib to open-label tofacitinib resulted in numerically higher incidence of responders for signs and symptoms of disease and improved physical function.
\end{abstract}

Conclusions: Treatment can be directly switched from adalimumab to tofacitinib. A similar safety and efficacy profile was seen when patients received open-label tofacitinib after receiving either blinded adalimumab or tofacitinib.

Trial registration: ClinicalTrials.gov Identifiers: NCT00853385, registered 27 February 2009; NCT00413699, registered 18 December 2006.

Keywords: Drug switching, Efficacy, Safety, Tofacitinib, Adalimumab, Rheumatoid arthritis

\footnotetext{
* Correspondence: Liza.Takiya@pfizer.com

${ }^{4}$ Pfizer Inc, 500 Arcola Drive, F5352, Collegeville, PA 19426, USA

Full list of author information is available at the end of the article
} 


\section{Background}

The long-term treatment of rheumatoid arthritis (RA) often involves a sequence of different therapies. Patients who have not responded to conventional synthetic disease-modifying anti-rheumatic drugs (DMARDs) have been routinely treated with a tumor necrosis factor inhibitor (TNFi); however, approximately $20 \%$ of patients discontinue TNFi therapy within 12 months due to inefficacy or adverse events (AEs) [1,2]. Management of patients who have not responded to treatment with one TNFi may involve switching to another TNFi or an agent with an alternative mechanism of action. Several randomized controlled trials have demonstrated the efficacy of agents with a different mechanism of action versus placebo in patients with an inadequate response to a TNFi [3-5]. In clinical practice, patients receiving a TNFi, such as adalimumab (ADA), may need or choose to switch to an agent with an alternative mechanism of action; an understanding of the impact of switching without an extended washout period is needed.

Tofacitinib is an oral Janus kinase inhibitor for the treatment of RA [6]. The tofacitinib phase 3 program included six randomized, controlled studies in which tofacitinib was assessed in adult patients with active moderate to severe RA [7-12] as monotherapy or combined with conventional synthetic DMARDs. A 12-month, double-blind, randomized, controlled trial, conducted in 115 centers worldwide, compared the safety and efficacy of tofacitinib 5 or $10 \mathrm{mg}$ twice daily (BID) or ADA $40 \mathrm{mg}$ every 2 weeks (Q2W) with placebo in patients with active RA taking background methotrexate (MTX; 7.5 to $25 \mathrm{mg}$ weekly), who had an inadequate response to MTX (defined as sufficient residual disease activity to meet entry criteria). The primary safety and efficacy data have been reported previously [10]. Eligible patients who had participated in this blinded study could be enrolled in an openlabel extension where they received tofacitinib $10 \mathrm{mg}$ BID (with or without background MTX), regardless of their treatment in the blinded study [13].

The objective of the current analyses was to describe the safety and efficacy of open-label tofacitinib in an extension study, following a direct switch from blinded treatment with either ADA or tofacitinib for the treatment of moderate to severe RA. The group of patients who received blinded tofacitinib followed by open-label tofacitinib in the extension study could act as a control for such an assessment by representing potential changes to the clinical profile introduced by transition from the double-blind to the open-label study with minimal changes in treatment (dose adjustments permitted for concomitant RA medications and tofacitinib in the extension study).

\section{Methods}

\section{Study design and treatment}

ORAL Standard (A3921064; NCT00853385) was a double-blind, phase 3 trial [10] in which patients were randomly assigned to one of five regimens, all with stable background MTX: tofacitinib $5 \mathrm{mg}$ BID, tofacitinib $10 \mathrm{mg}$ BID, ADA $40 \mathrm{mg}$ Q2W (subcutaneous injection), placebo for 3 or 6 months followed by tofacitinib $5 \mathrm{mg}$ BID, and placebo for 3 or 6 months followed by tofacitinib $10 \mathrm{mg}$ BID for a total of 12 months.

ORAL Sequel (A3921024; NCT00413699) is an openlabel long-term extension study [13] in which all patients from ORAL Standard were eligible to receive tofacitinib $10 \mathrm{mg}$ BID with or without conventional synthetic DMARDs. Exclusion criteria included treatment-related serious AEs and serious or recurrent infections (including serious or recurrent herpes zoster) in the index study. Patients with latent tuberculosis were allowed to continue in the extension study if they had received an adequate course of therapy. Patients from certain countries (e.g., Korea, Croatia, Denmark, Czech Republic, Germany, Spain, Sweden, Ireland and the United Kingdom) who enrolled in the extension study $\geq 14$ days after their final index study visit were excluded if their absolute lymphocyte count (ALC) values were $<750$ cells $/ \mathrm{mm}^{3}$. Patients from the remaining countries were excluded if their ALC values were $<500$ cells $/ \mathrm{mm}^{3}$.

The current post-hoc analyses included patients who were randomized at baseline to treatment with blinded ADA $40 \mathrm{mg}$ Q2W + MTX or blinded tofacitinib $10 \mathrm{mg}$ BID + MTX in ORAL Standard and subsequently received open-label tofacitinib $10 \mathrm{mg}$ BID (with or without MTX) in the extension study. Although the patients initiated treatment in the long-term extension with tofacitinib $10 \mathrm{mg}$ BID, this could be reduced to $5 \mathrm{mg}$ BID for safety reasons. Additionally, dose adjustments, including tapering and discontinuation (DC) of permitted concomitant RA medications (such as MTX, prednisone and non-steroidal anti-inflammatory drugs) were allowed in response to inadequate efficacy, disease improvement, or for safety reasons.

Each study was performed in compliance with the Declaration of Helsinki and Good Clinical Practice Guidelines established by the International Conference on Harmonization. The final protocols, amendments, and informed consent documentation were reviewed and approved by the institutional review board and the independent ethics committee of each investigational center (Additional file 1: Table S1).

\section{Patients}

Patients in this analysis included those who were initially enrolled in the phase 3, ORAL Standard study [10] and subsequently elected to enroll in the extension study [13]. Eligible patients in the phase 3 study were $\geq 18$ years 
of age and had received a diagnosis of active RA, as classified according to the American College of Rheumatology (ACR) 1987 Revised Criteria [14] and had not failed or had an AE to a TNFi in the past. Additional inclusion and exclusion criteria have been described previously [10]. Patients who completed participation in the study or discontinued for reasons other than treatment-related serious AEs and who met other inclusion/exclusion criteria were invited to enroll in the long-term extension [13]. For patients enrolling in the long-term extension study within 2 weeks of their last dose in the blinded study, baseline values were obtained from the blinded study.

\section{Statistical analyses}

Post-hoc descriptive statistics are reported (data cutoff date 19 April 2012). As the extension study is ongoing, the study database has not yet been locked (i.e., some values may change for the final, locked study database).

\section{Safety and tolerability assessments}

The incidence of treatment-emergent AEs (TEAEs) was calculated at scheduled visits of the blinded study (baseline, and months 1, 3, 6, 9, and 12) and extension study (baseline, months $1,2,3$, and every 3 months thereafter).

In the current analyses, the incidence of TEAEs was compared during the last 3 months of blinded therapy and the first 3 months of open-label treatment.

Exposure-adjusted incidence rates (and corresponding $95 \%$ confidence intervals) of DCs due to AEs, serious AEs and serious infections per 100 patient-years from baseline were calculated for patients who completed treatment with ADA $40 \mathrm{mg}$ Q2W + MTX or tofacitinib

Table 1 Baseline characteristics for patients randomized to double-blind adalimumab (ADA) 40 mg every 2 weeks or tofacitinib 10 mg twice daily (BID) in the phase 3 study [10] and for the subgroup who then received open-label tofacitinib $10 \mathrm{mg}$ BID in the extension study [13]

\begin{tabular}{|c|c|c|c|c|}
\hline & \multicolumn{2}{|c|}{ Double-blind study } & \multicolumn{2}{|c|}{ Double-blind to open-label extension ${ }^{a}$} \\
\hline & ADA $40 \mathrm{mg}$ & Tofacitinib 10 mg & ADA to tofacitinib & Tofacitinib to tofacitinib \\
\hline & $n=204$ & $n=201$ & $n=107$ & $n=126$ \\
\hline Female, n (\%) & $162(79.4)$ & $168(83.6)$ & $83(77.6)$ & $107(84.9)$ \\
\hline White, n (\%) & $148(72.5)$ & $143(71.1)$ & $90(84.1)$ & $98(77.8)$ \\
\hline Age in years, mean $\pm S D$ & $52.5 \pm 11.7$ & $52.9 \pm 11.8$ & $52.2 \pm 11.4$ & $51.6 \pm 11.2$ \\
\hline \multicolumn{5}{|l|}{ Region of origin, $\%$} \\
\hline North America & 25.5 & 24.9 & 16.8 & 20.6 \\
\hline South America & 2.9 & 1.5 & 4.7 & 1.6 \\
\hline Europe & 53.9 & 55.7 & 60.7 & 59.5 \\
\hline Rest of world & 17.6 & 17.9 & 17.8 & 18.3 \\
\hline \multicolumn{5}{|l|}{ Tender and swollen joints, mean } \\
\hline Tender & 26.7 & 26.1 & 28.0 & 25.6 \\
\hline Swollen & 16.4 & 15.8 & 16.8 & 16.1 \\
\hline Mean HAQ-DI score & 1.5 & 1.5 & 1.5 & 1.5 \\
\hline Mean DAS28-4(ESR) & 6.4 & 6.5 & 6.4 & 6.4 \\
\hline Mean CRP (mg/L) & 17.5 & 17.3 & 16.2 & 17.9 \\
\hline Positive for rheumatoid factor, $\%$ & 68.2 & 66.2 & 66.4 & 65.9 \\
\hline Positive for anti-CCP, \% & 74.8 & 64.0 & 74.8 & 65.1 \\
\hline \multicolumn{5}{|l|}{ Prior therapy, n (\%) } \\
\hline TNF inhibitor & $16(7.8)$ & $14(7.0)$ & $12(11.2)$ & $10(7.9)$ \\
\hline Non-TNF inhibitor biologic agent & $3(1.5)$ & $4(2.0)$ & $1(0.9)$ & $3(2.4)$ \\
\hline Disease-modifying drug other than MTX & $114(55.9)$ & $115(57.2)$ & $66(61.7)$ & $80(63.5)$ \\
\hline \multicolumn{5}{|l|}{ Concomitant therapy, n (\%) } \\
\hline Glucocorticoids & $125(61.3)$ & $129(64.2)$ & $63(58.9)$ & $77(61.1)$ \\
\hline Lipid-lowering medication & $10(4.9)$ & $10(5.0)$ & $6(5.6)$ & $6(4.8)$ \\
\hline
\end{tabular}

${ }^{a}$ Baseline values at the start of the double-blind study; includes patients who completed treatment with ADA 40 mg every 2 weeks or tofacitinib 10 mg BID in the blinded study (or discontinued treatment for reasons other than a tofacitinib-related serious adverse event (AE)) and then enrolled in the extension study and switched treatment with minimal washout ( $\leq 2$ weeks after their last dose of study drug in the blinded study). CCP cyclic citrullinated peptide, $C R P C$-reactive protein, DAS28-4(ESR) Disease Activity Score for 28-joint counts based on the erythrocyte sedimentation rate, HAQ-DI Health Assessment Questionnaire-Disability Index, MTX methotrexate, RA rheumatoid arthritis, SD standard deviation, TNF tumor necrosis factor 
$10 \mathrm{mg}$ BID + MTX in the blinded study for patients, (1) regardless of whether they entered the extension study, and (2) who then enrolled in the extension study. These analyses were performed for 3 -month (months $0-3$, $3-6,6-9$, and 9-12) and 12-month (months $0-12$ ) periods for both the blinded study and the first 12 months of the extension study. Of note, there were two study visits in the last 3 months of the blinded study (visits 5 and 6 at months 9 and 12, respectively), and four study visits in the first 3 months of the extension study (visits $1-4$, for baseline and months 1,2 , and 3 ).

\section{Efficacy assessments}

The following efficacy parameters were measured in patients who completed treatment with ADA + MTX or tofacitinib $10 \mathrm{mg}+$ MTX in the blinded study (or discontinued for reasons other than a treatment-related serious $\mathrm{AE}$ ) and then switched to the tofacitinib $10 \mathrm{mg}$ group in the extension study: ACR response rates (20\%, $50 \%$, and $70 \%$ improvement), mean change in Health Assessment Questionnaire-Disability Index (HAQ-DI) scores from the baseline of the blinded study, and Disease Activity Score for 28-joint counts based on the erythrocyte sedimentation rate (DAS28-4(ESR)) $<2.6$ response rates at: (1) month 9 (visit 5) of the blinded study ("-3 months" relative to the switch); (2) the time of switching from the blinded to the extension study ("switch"), and (3) month 3 (visit 4) of the extensions study ("+ +3 months") allowing visit windows of \pm 1.5 months to capture all efficacy and safety data.

Table 2 Incidence of treatment-emergent adverse events (TEAEs), and the most commonly reported TEAEs (occurring in $\geq 2 \%$ of patients in any group) during the last 3 months of the double-blind phase 3 study [10] and the first 3 months of the open-label extension [13]

\begin{tabular}{|c|c|c|c|c|}
\hline & \multicolumn{2}{|l|}{$\begin{array}{l}\text { ADA to tofacitinib } \\
n=107\end{array}$} & \multicolumn{2}{|l|}{$\begin{array}{l}\text { Tofacitinib to tofacitinib } \\
n=126\end{array}$} \\
\hline & $\begin{array}{l}-3 \text { months to switch } \\
\text { (ADA) }\end{array}$ & $\begin{array}{l}\text { Switch to +3 months } \\
\text { (tofacitinib) }\end{array}$ & $\begin{array}{l}-3 \text { months to switch } \\
\text { (tofacitinib) }\end{array}$ & $\begin{array}{l}\text { Switch to }+3 \text { months } \\
\text { (tofacitinib) }\end{array}$ \\
\hline \multicolumn{5}{|l|}{ Safety summary } \\
\hline \multicolumn{5}{|l|}{ Number of patients (\%) } \\
\hline DCs due to AEs & 0 & $3(2.8)$ & $1(0.8)$ & $3(2.4)$ \\
\hline Serious AEs & $1(0.9)$ & $8(7.5)$ & $4(3.2)$ & $8(6.3)$ \\
\hline Serious infections & 0 & $2(1.9)$ & $1(0.8)$ & $2(1.6)$ \\
\hline Deaths & 0 & $2(1.9)^{a}$ & 0 & 0 \\
\hline \multicolumn{5}{|l|}{ Most commonly reported TEAEs } \\
\hline \multicolumn{5}{|l|}{ Number of patients (\%) } \\
\hline Abdominal pain upper & 0 & $1(0.9)$ & $4(3.2)$ & $1(0.8)$ \\
\hline Arthralgia & 0 & $1(0.9)$ & $4(3.2)$ & $2(1.6)$ \\
\hline Bronchitis & $4(3.7)$ & $3(2.8)$ & $6(4.8)$ & $2(1.6)$ \\
\hline Cough & 0 & $1(0.9)$ & $1(0.8)$ & $3(2.4)$ \\
\hline Depression & 0 & $1(0.9)$ & $3(2.4)$ & $1(0.8)$ \\
\hline Fall & $1(0.9)$ & $1(0.9)$ & $3(2.4)$ & $1(0.8)$ \\
\hline Hemoglobin decreased & 0 & $3(2.8)$ & 0 & $1(0.8)$ \\
\hline Headache & 0 & $2(1.9)$ & 0 & $2(1.6)$ \\
\hline Nasopharyngitis & $2(1.9)$ & $4(3.7)$ & $5(4.0)$ & $3(2.4)$ \\
\hline Nausea & $1(0.9)$ & $3(2.8)$ & $1(0.8)$ & $1(0.8)$ \\
\hline Edema peripheral & $1(0.9)$ & 0 & $2(1.6)$ & $3(2.4)$ \\
\hline Oropharyngeal pain & 0 & 0 & 0 & $3(2.4)$ \\
\hline Upper respiratory tract infection & $3(2.8)$ & $5(4.7)$ & $3(2.4)$ & $6(4.8)$ \\
\hline Urinary tract infection & 0 & $5(4.7)$ & $2(1.6)$ & 0 \\
\hline Vomiting & 0 & $2(1.9)$ & $1(0.8)$ & 0 \\
\hline Worsening RA & 0 & 0 & $3(2.4)$ & $2(1.6)$ \\
\hline
\end{tabular}


Table 3 Adverse events and change from baseline in selected laboratory variables during the phase 3 double-blind study [10] and the open-label extension study [13]

\begin{tabular}{|c|c|c|c|c|c|c|c|c|c|c|}
\hline \multirow[b]{2}{*}{$\begin{array}{l}\text { IR per } 100 \text { patient-years } \\
(95 \% \mathrm{Cl})\end{array}$} & \multicolumn{5}{|c|}{ Double-blind study ${ }^{a}$} & \multicolumn{5}{|c|}{ Open-label extension study ${ }^{b}$} \\
\hline & $0-3$ months & $3-6$ months & $6-9$ months & $9-12$ months & Total 12 months & $0-3$ months & $3-6$ months & $6-9$ months & $9-12$ months & $\begin{array}{l}\text { Total } \\
12 \text { months }\end{array}$ \\
\hline \multicolumn{11}{|c|}{ ADA 40 mg Q2W (blinded study) to tofacitinib 10 mg BID (extension study) } \\
\hline & \multicolumn{5}{|c|}{ ADA $40 \mathrm{mg}$ Q2W } & \multicolumn{5}{|c|}{ Tofacitinib 10 mg BID } \\
\hline & $N=204$ & $N=187$ & $N=177$ & $N=163$ & $N=204$ & $N=145$ & $N=130$ & $N=124$ & $N=121$ & $N=145$ \\
\hline DCs due to AEs & $16.3(9.0,29.5)$ & $19.2(9.6,38.4)$ & $6.7(2.1,20.7)$ & $4.1(0.6,29.3)$ & $12.9(8.6,19.4)$ & $10.0(4.2,24.0)$ & $9.6(3.1,29.9)$ & $3.3(0.5,23.6)$ & $12.0(3.9,37.2)$ & $8.8(5.0,15.6)$ \\
\hline Serious AES & $8.9(4.0,19.9)$ & $16.8(8.0,35.2)$ & $6.7(2.2,20.7)$ & $8.2(2.1,32.9)$ & $10.3(6.5,16.3)$ & $16.1(8.0,32.2)$ & $16.2(6.8,39.0)$ & $6.7(1.7,26.7)$ & $8.0(2.0,31.8)$ & $13.0(8.1,20.9)$ \\
\hline Serious infections & 0 & $4.8(1.2,19.1)$ & $2.2(0.3,15.8)$ & 0 & $1.7(0.5,5.2)$ & $4.0(1.0,15.9)$ & 0 & $3.3(0.5,23.7)$ & $4.0(0.6,28.1)$ & $2.9(1.1,7.9)$ \\
\hline \multicolumn{11}{|c|}{ Tofacitinib 10 mg BID (blinded study) to tofacitinib 10 mg BID (extension study) } \\
\hline & \multicolumn{5}{|c|}{ Tofacitinib 10 mg BID } & \multicolumn{5}{|c|}{ Tofacitinib 10 mg BID } \\
\hline & $N=201$ & $N=184$ & $N=173$ & $N=157$ & $N=201$ & $N=146$ & $N=128$ & $N=122$ & $N=109$ & $N=146$ \\
\hline DCs due to AEs & $16.7(9.3,30.2)$ & $22.2(11.6,42.7)$ & $6.8(2.2,21.1)$ & $0.0(0.0,0.0)$ & $13.3(8.8,20.0)$ & $13.9(6.6,29.1)$ & $3.3(0.5,23.2)$ & $10.5(3.4,32.5)$ & $4.4(0.6,31.5)$ & $9.1(5.2,16.0)$ \\
\hline Serious AEs & $20.1(11.6,34.5)$ & $12.3(5.1,29.6)$ & $9.1(3.4,24.2)$ & $8.7(2.2,34.8)$ & $13.7(9.1,20.6)$ & $18.0(9.4,34.6)$ & $9.9(3.2,30.6)$ & $14.0(5.3,37.3)$ & $4.4(0.6,31.5)$ & $13.4(8.3,21.5)$ \\
\hline \multirow[t]{2}{*}{ Serious infections } & $4.6(1.5,14.2)$ & $2.4(0.3,17.3)$ & $4.5(1.1,18.1)$ & $4.3(0.6,30.7)$ & $4.0(1.9,8.4)$ & $5.9(1.9,18.4)$ & $3.3(0.5,23.2)$ & $3.5(0.5,24.8)$ & $4.4(0.6,31.5)$ & $4.5(2.0,10.1)$ \\
\hline & \multicolumn{5}{|c|}{ Double-blind study ${ }^{b}$} & \multicolumn{5}{|c|}{ Long-term extension study ${ }^{\mathrm{b}}$} \\
\hline $\begin{array}{l}\text { Mean change from } \\
\text { baseline (SD) }\end{array}$ & Month 1 & Month 3 & Month 6 & Month 9 & Month 12 & Month 1 & Month 3 & Month 6 & Month 9 & Month 12 \\
\hline \multicolumn{11}{|c|}{ ADA 40 mg Q2W (blinded study) to tofacitinib 10 mg BID (extension study) } \\
\hline & \multicolumn{5}{|c|}{ ADA $40 \mathrm{mg}$ Q2W } & \multicolumn{5}{|c|}{ Tofacitinib 10 mg BID } \\
\hline & $N=142$ & $N=142$ & $N=141$ & $N=138$ & $N=132$ & $N=132$ & $N=126$ & $N=118$ & $N=118$ & $N=110$ \\
\hline \multirow{2}{*}{$\begin{array}{l}\text { Absolute lymphocyte count, } \\
\text { cells } / \mathrm{mm}^{3}\end{array}$} & $0.4(0.6)$ & $0.4(0.6)$ & $0.4(0.6)$ & $0.4(0.6)$ & $0.4(0.7)$ & $0.5(0.8)$ & $0.2(0.6)$ & $0.0(0.6)$ & $-0.0(0.6)$ & $-0.0(0.6)$ \\
\hline & $N=142$ & $N=144$ & $N=144$ & $N=140$ & $N=137$ & $N=139$ & $N=131$ & $N=125$ & $N=122$ & $N=115$ \\
\hline \multirow[t]{2}{*}{ Total cholesterol, mg/dL } & $8.3(26.4)$ & $6.7(30.1)$ & $2.8(29.4)$ & $-0.1(29.7)$ & $3.2(33.9)$ & $22.8(33.2)$ & $24.5(38.2)$ & $18.9(36.4)$ & $20.8(35.6)$ & $18.8(37.7)$ \\
\hline & $N=140$ & $N=141$ & $N=142$ & $N=139$ & $N=134$ & $N=1$ & $N=3$ & $N=121$ & $N=2$ & $N=107$ \\
\hline \multirow[t]{2}{*}{ LDL, mg/dL } & $3.2(20.5)$ & $2.5(24.9)$ & $0.5(24.3)$ & $-3.5(23.1)$ & $-1.8(27.0)$ & $18.9(\mathrm{~N} / \mathrm{A})$ & $-6.2(57.8)$ & $6.2(30.2)$ & $36.0(25.5)$ & $8.6(31.9)$ \\
\hline & $N=142$ & $N=144$ & $N=143$ & $N=140$ & $N=135$ & $N=1$ & $N=3$ & $N=122$ & $N=2$ & $N=108$ \\
\hline \multirow[t]{2}{*}{$\mathrm{HDL}, \mathrm{mg} / \mathrm{dL}$} & $3.3(9.2)$ & $3.4(10.0)$ & $1.6(11.3)$ & $3.3(11.5)$ & $5.6(10.5)$ & 20.9 (N/A) & $13.1(24.5)$ & $11.9(11.8)$ & $10.5(30.4)$ & $8.8(12.3)$ \\
\hline & $N=142$ & $N=144$ & $N=143$ & $N=140$ & $N=135$ & $N=1$ & $N=5$ & $N=122$ & $N=3$ & $N=108$ \\
\hline Triglycerides, mg/dL & $7.8(49.9)$ & $2.8(41.2)$ & $2.7(45.8)$ & $-0.1(58.7)$ & $-6.0(48.9)$ & $5.3(\mathrm{~N} / \mathrm{A})$ & $2.0(53.2)$ & $4.7(57.1)$ & $8.0(13.6)$ & $3.1(54.8)$ \\
\hline
\end{tabular}


Table 3 Adverse events and change from baseline in selected laboratory variables during the phase 3 double-blind study [10] and the open-label extension study [13] (Continued)

\begin{tabular}{|c|c|c|c|c|c|c|c|c|c|c|}
\hline \multicolumn{11}{|c|}{ Tofacitinib 10 mg BID (blinded study) to tofacitinib 10 mg BID (extension study) } \\
\hline & \multicolumn{5}{|c|}{ Tofacitinib $10 \mathrm{mg} \mathrm{BID}$} & \multicolumn{5}{|c|}{ Tofacitinib $10 \mathrm{mg} \mathrm{BID}$} \\
\hline & $N=142$ & $N=141$ & $N=141$ & $N=138$ & $N=129$ & $N=134$ & $N=131$ & $N=116$ & $N=112$ & $N=103$ \\
\hline \multirow{2}{*}{$\begin{array}{l}\text { Absolute lymphocyte count, } \\
\text { cells } / \mathrm{mm}^{3}\end{array}$} & $0.2(0.5)$ & $-0.0(0.5)$ & $-0.1(0.6)$ & $-0.1(0.6)$ & $-0.3(0.6)$ & $-0.1(0.6)$ & $-0.2(0.6)$ & $-0.3(0.6)$ & $-0.3(0.6)$ & $-0.3(0.6)$ \\
\hline & $N=145$ & $N=142$ & $N=141$ & $N=136$ & $N=131$ & $N=136$ & $N=134$ & $N=122$ & $N=117$ & $N=106$ \\
\hline \multirow[t]{2}{*}{ Total cholesterol, mg/dL } & $28.7(29.2)$ & $27.4(31.7)$ & $30.0(34.3)$ & $29.3(36.6)$ & $32.8(37.2)$ & 30.6 (33.9) & $27.6(38.8)$ & $22.5(42.2)$ & $23.7(36.3)$ & $29.7(32.7)$ \\
\hline & $N=141$ & $N=139$ & $N=137$ & $N=133$ & $N=123$ & $N=0$ & $N=5$ & $N=117$ & $N=4$ & $N=100$ \\
\hline \multirow[t]{2}{*}{$\mathrm{LDL}, \mathrm{mg} / \mathrm{dL}$} & 18.7 (25.6) & $19.1(25.5)$ & 20.7 (31.0) & $19.8(31.1)$ & $20.0(31.8)$ & $\mathrm{N} / \mathrm{A}$ & $9.8(28.4)$ & $13.1(35.8)$ & $16.3(42.5)$ & $20.7(30.7)$ \\
\hline & $N=145$ & $N=142$ & $N=141$ & $N=136$ & $N=127$ & $N=0$ & $N=5$ & $N=121$ & $N=4$ & $N=103$ \\
\hline \multirow[t]{2}{*}{$\mathrm{HDL}, \mathrm{mg} / \mathrm{dL}$} & $8.0(12.4)$ & $6.1(14.1)$ & $7.7(17.9)$ & $7.1(15.4)$ & $8.2(15.7)$ & N/A & $16.1(19.0)$ & $8.6(19.1)$ & $7.9(3.9)$ & $9.0(15.2)$ \\
\hline & $N=145$ & $N=142$ & $N=141$ & $N=136$ & $N=127$ & $N=0$ & $N=7$ & $N=121$ & $N=4$ & $N=103$ \\
\hline Triglycerides, mg/dL & $9.2(65.0)$ & $8.4(69.4)$ & $13.0(87.3)$ & $12.3(91.0)$ & $15.0(83.3)$ & N/A & $25.5(69.2)$ & $12.9(84.8)$ & $6.6(61.7)$ & $7.5(70.1)$ \\
\hline
\end{tabular}

ancludes patients who were treated with adalimumab (ADA) $40 \mathrm{mg}$ every 2 weeks (Q2W) or tofacitinib $10 \mathrm{mg}$ twice daily (BID) from baseline in the blinded study, regardless of whether they entered the extension study. ${ }^{b}$ Includes all patients who completed treatment with ADA $40 \mathrm{mg}$ Q2W or tofacitinib $10 \mathrm{mg}$ BID in the blinded study and then switched treatment and completed 12 months of the extension study. Please see "Methods" for important exceptions. AE adverse event, CI confidence interval, DC discontinuation, HDL high-density lipoprotein, IR incidence rate, LDL low density lipoprotein, N/A not available 


\section{Results}

\section{Patient disposition and demographics}

Of 204 patients randomized to ADA $40 \mathrm{mg}$ Q2W + MTX in the blinded study, 107 switched to open-label tofacitinib $10 \mathrm{mg}$ BID (105 (98 \%) with MTX on day 1) within 2 weeks after their last dose of ADA. Of 201 patients randomized to blinded tofacitinib $10 \mathrm{mg}$ BID + MTX in the blinded study, 126 switched to open-label tofacitinib $10 \mathrm{mg}$ BID (123 (98 \%) with MTX on day 1) within 2 weeks. Patient demographic and baseline characteristics were similar across sequences and between those patients who were randomized to ADA $40 \mathrm{mg}$ Q2W + MTX or tofacitinib $10 \mathrm{mg}$ BID + MTX in the blinded study and those who then received tofacitinib $10 \mathrm{mg}$ BID (with or without MTX) in the extension study (Table 1).

\section{Safety and tolerability}

On analysis of the proportions of patients with TEAEs occurring 3 months prior to and 3 months after the switch, there was no clear pattern of changes in either the ADA to tofacitinib group or the blinded to openlabel tofacitinib group (Table 2). Incidence rates per 100 patient-years of DCs due to AEs, serious AEs, and serious infections over 3-month and 12-month periods were similar in the year before and in the year after switching in both groups (Table 3). Incidence rates were increased in the first 3 months of the extension study (0-3 months) compared with the last 3 months of the blinded study ( $9-12$ months) for both groups.

In the extension study, small increases from baseline in ALC were observed at month 1 and month 3 in patients in the ADA to tofacitinib group; ALC levels returned to baseline at month 6 and were maintained through month 12 . Small decreases from baseline in ALC were observed at all time points through month 12 in patients in the blinded to open-label tofacitinib group (Table 3). In the extension study, patients in the ADA to tofacitinib group and patients in the blinded to open-label tofacitinib group had small increases from baseline in total cholesterol, low-density lipoprotein (LDL), high-density lipoprotein (HDL) and triglycerides at all time points through month 12 (except for LDL at month 3 in patients in the ADA to tofacitinib group) (Table 3). At month 3 of the extension study, 2 patients $(2 \%)$ in the ADA to tofacitinib group and 4 patients $(3 \%)$ in the blinded to open-label tofacitinib group were receiving lipid-lowering agents.

Table 4 Patient-level serious adverse events from switch to +3 months

\begin{tabular}{|c|c|c|c|}
\hline Serious AE & $\begin{array}{l}\text { Days after first tofacitinib dose } \\
\text { in the extension study }\end{array}$ & $\begin{array}{l}\text { Action taken } \\
\text { (tofacitinib dosing) }\end{array}$ & Outcome \\
\hline \multicolumn{4}{|c|}{ ADA 40 mg Q2W (blinded study) to tofacitinib 10 mg BID (extension study), N = 107} \\
\hline Suicide $(n=1)$ & $1^{a}$ & Permanently withdrawn & Death \\
\hline Osteonecrosis $(n=1)$ & 23 & Temporarily withdrawn & Recovered \\
\hline Post-operative abscess $(n=1)$ & 44 & Dose not changed & Recovered \\
\hline $\begin{array}{l}\text { Infectious peritonitis/appendicitis/intervertebral disc } \\
\text { disorder ( } n=1 \text { each; same patient) }\end{array}$ & $44 / 46 / 51$ & Permanently withdrawn & Recovered \\
\hline Autoimmune hepatitis (possible drug-induced liver injury; $\mathrm{n}=1$ ) & 55 & Permanently withdrawn & Recovered \\
\hline Fractured ischium $(n=1)$ & 109 & Temporarily withdrawn & Recovering \\
\hline $\begin{array}{l}\text { Spondylolisthesis/stenosis/lung malignancy ( } \mathrm{n}=1 \text { each; } \\
\text { same patient) }\end{array}$ & $117 / 117 / 132$ & Not applicable & Death $^{b}$ \\
\hline Fractured femur $(n=1)$ & 134 & Temporarily withdrawn & Recovered \\
\hline \multicolumn{4}{|c|}{ Tofacitinib 10 mg BID (blinded study) to tofacitinib 10 mg BID (extension study), N = 126} \\
\hline Sinusitis $(n=1)$ & 13 & Permanently withdrawn & Recovered \\
\hline Dyspnea/tendon rupture ( $\mathrm{n}=1$ each; same patient) & $37 / 53$ & Temporarily withdrawn & Recovered \\
\hline Cervical dysplasia $(n=1)$ & 52 & Permanently withdrawn & Recovered \\
\hline Malignant melanoma $(n=1)$ & 85 & Permanently withdrawn & Recovered \\
\hline Vertigo $(n=1)$ & 89 & Dose not changed & Not recovered \\
\hline Disseminated herpes simplex $(n=1)$ & 94 & Permanently withdrawn & Recovered \\
\hline Cervical vertebral fracture/fall ( $n=1$ each; same patient) & $102 / 102$ & Dose not changed & Recovering \\
\hline Lung infiltration/atrial fibrillation $(\mathrm{n}=1 \text { each; same patient })^{c}$ & $107 / 122$ & Permanently withdrawn & Recovered/not applicable \\
\hline Goiter $(n=1)$ & 120 & Temporarily withdrawn & Recovered \\
\hline
\end{tabular}

Includes patients who completed treatment with adalimumab (ADA) 40 mg every 2 weeks (Q2W) or tofacitinib 10 mg twice daily (BID) in the blinded study (or discontinued treatment for reasons other than a tofacitinib-related serious adverse event (AE)) and then enrolled in the extension study and switched treatment with minimal washout ( $\leq 2$ weeks after their last dose of study drug in the blinded study). ${ }^{\mathrm{a}}$ Unknown whether the patient took study drug on this day. ${ }^{\mathrm{b}}$ Due to lung malignancy. ${ }^{\mathrm{C}} \mathrm{Atrial}$ fibrillation (day 122) occurred after drug discontinuation (day 107) 
Serious AEs occurring up to the month-3 visit of the extension study - that is, following the switch to tofacitinib are presented in Table 4 alongside the action taken and patient outcomes. Two serious AEs resulted in death (lung malignancy, $\mathrm{n}=1$ (day 132); suicide, $\mathrm{n}=1$ (day 1 ); it is unknown whether the patient took the study drug on this day). One patient who developed vertigo during this period was still experiencing it 20 months later. All other patients who experienced a serious $\mathrm{AE}$ in the first 3 months of the extensions study recovered from the $\mathrm{AE}$.

\section{Efficacy}

Greater proportions of patients had improvement in the signs and symptoms of RA, as measured by increased ACR response rates (Fig. 1) and reductions in mean DAS28-4(ESR), during the first 3 months of the extension study compared with the last 3 months of the blinded study in both the ADA to tofacitinib group and the blinded to open-label tofacitinib group (Fig. 2a). Of the 74 patients on $\mathrm{ADA}$ and 84 patients on tofacitinib who achieved an ACR20 response 3 months prior to switching in the double-blind study, $7 \%(\mathrm{n}=5)$ and $7 \%(n=6)$, respectively, did not maintain an ACR20 response 3 months after switching to tofacitinib in the extension study.
Similarly, further improvement in physical function, as measured by greater mean reductions in HAQ-DI score from baseline, was seen in both treatment groups (Fig. 2b).

\section{Discussion}

The clinical, functional, and radiographic efficacy and safety of tofacitinib 5 and $10 \mathrm{mg}$ BID with and without MTX has been reported in patients with active RA in randomized phase 2 [15-19] and phase 3 studies [7-12]. The phase 3 study that included an ADA treatment arm demonstrated efficacy and safety results of tofacitinib consistent with the other phase 3 studies [10]. The current analyses describe the safety and efficacy of open-label tofacitinib (with or without MTX) following a direct switch from blinded treatment with either ADA + MTX or tofacitinib + MTX.

Both proportions and exposure-adjusted incidence rates of DCs due to AEs, serious AEs, and serious infections over time were similar when switching from blinded ADA or tofacitinib to open-label tofacitinib. The increased incidence rates for these events in the initial 3 months of open-label tofacitinib, compared with the last 3 months of either blinded ADA or tofacitinib, suggests that these differences may be due to aspects of the study design inherent in the transition period rather than as a result of any overlapping immunomodulatory effects of ADA and tofacitinib. One potential explanation for the observed

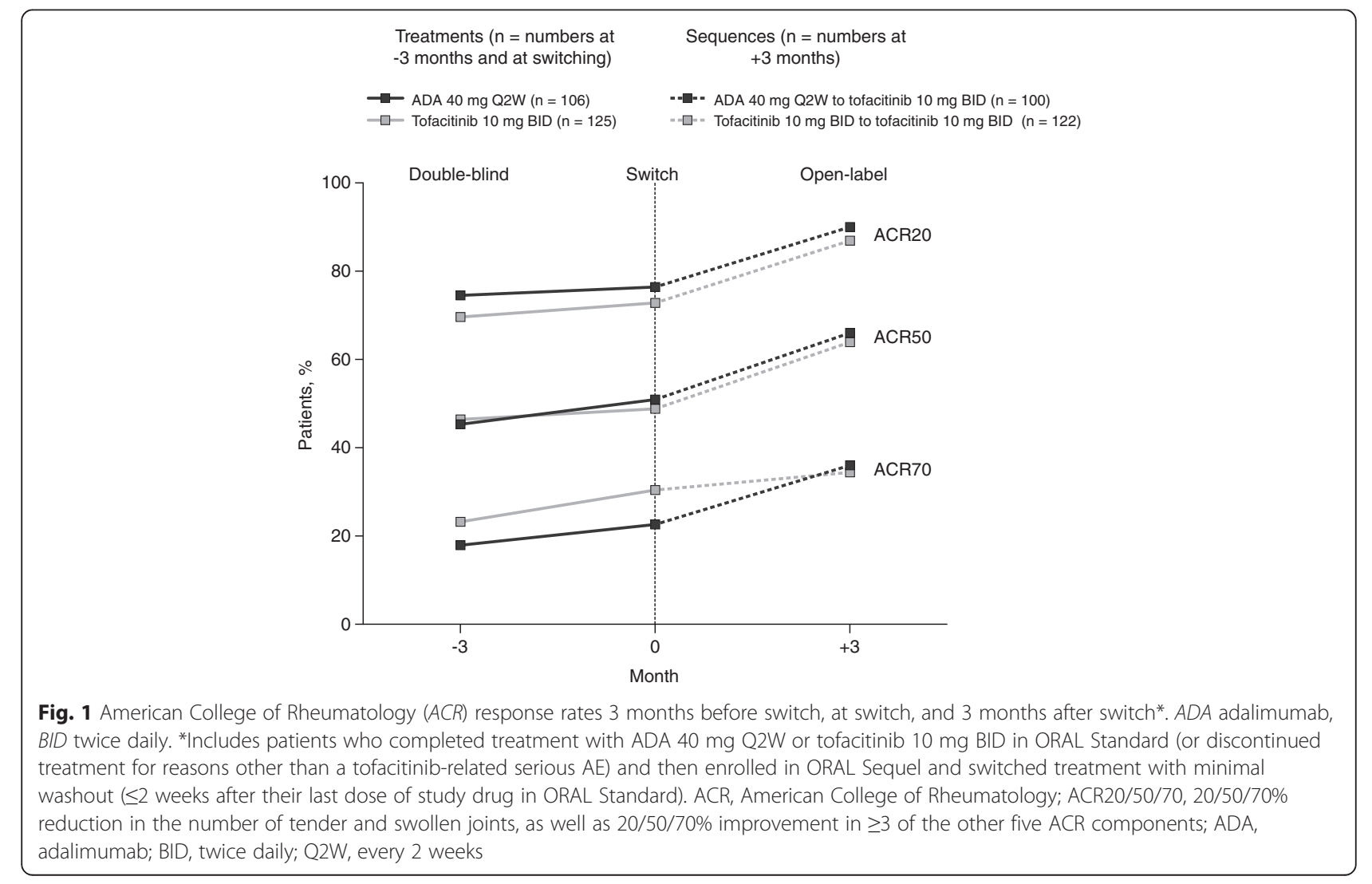



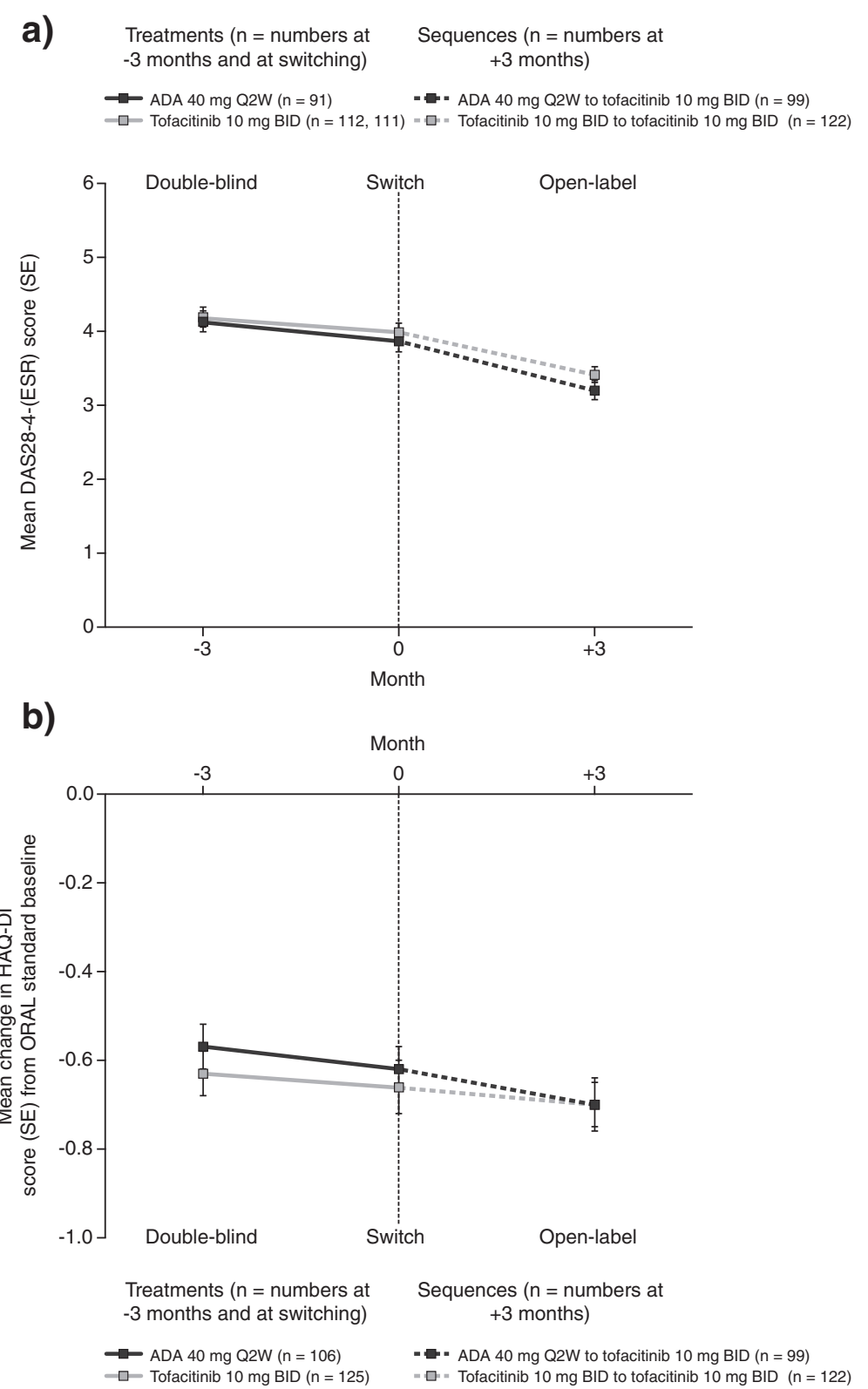

Fig. 2 Disease Activity Score for 28-joint counts based on the erythrocyte sedimentation rate (DAS28-4(ESR)) and changes from baseline in the Health Assessment Questionnaire-Disability Index (HAQ-DI) 3 months before switch, at switch, and 3 months after switch*. ADA adalimumab, BID twice daily. *Includes patients who completed treatment with ADA 40 mg Q2W or tofacitinib $10 \mathrm{mg}$ BID in ORAL Standard (or discontinued treatment for reasons other than a tofacitinib-related serious AE) and then enrolled in ORAL Sequel and switched treatment with minimal washout ( $\leq 2$ weeks after their last dose of study drug in ORAL Standard). Lower scores indicate less disease activity (DAS28-4[ESR]) or lower disability (HAQ-DI). ADA, adalimumab; BID, twice daily; DAS28-4(ESR), Disease Activity Score for 28 joint counts based on the erythrocyte sedimentation rate; HAQ-DI, Health Assessment Questionnaire-Disability Index; Q2W, every 2 weeks; SE, standard error. (a) Changes from Baseline in Disease Activity Score for 28joint counts based on Erythrocyte sedimentation rate (DAS28-4(ESR) 3 months before switch, at switch, and 3 months after switch.* (b) Changes from Baseline in the Health Assessment QUestionnaire-Disability Index (HAQ-DI) 3 months before switch, at switch, and 3 months after switch*

changes is the possibility of a measurement/detection effect. For example, the transition from the double-blind study to the open-label extension study may have driven an increase in patient/investigator sensitivity to reporting, whereby there was increased attribution of events in the extension study. Another limitation could have been the number of visits per 3-month period. Patients in the extension study had more frequent visits over the first 3 months of treatment (four visits) than they had in the final 3 months of the blinded study (two visits); thus, there were more opportunities to report an event in the first 3 months after the switch, which could have had an 
impact on the apparent incidence rate. Although a mechanistic or immunologic origin for the difference in safety profile cannot be ruled out, it is thought to be unlikely, as an increase was observed in both treatment sequences. On analysis of the proportions of patients experiencing TEAEs for 3 months before and 3 months after the switch, there was no clear pattern of changes during the switch. A further limitation is the potential change in dosing of permitted concomitant RA medications, including MTX, after switching.

Although the analyses of incidence rates per 100 patient-years of AEs in the blinded study included all patients regardless of whether they entered the extension, the data for the extension study included only those patients who completed the blinded study (that is, those who had data for the last 3 months of this study and who then enrolled in the extension). This introduces a potential censoring/truncation effect that is associated with identifying and analyzing a "completer" population. This effect may also apply to the efficacy response: patients with lesser efficacy responses may have been less likely to remain in the extension study to month 3 , thereby, leading to seemingly greater improvements at month 3 among patients in this study. However, the incidence of both DCs and improvements in efficacy during the first 3 months of the extension study were similar between those patients who switched to ADA and those who continued to receive tofacitinib.

With these limitations in mind, we observed that switching directly from double-blind ADA $40 \mathrm{mg}$ Q2W to open-label tofacitinib $10 \mathrm{mg}$ BID resulted in sustained clinical response, with numeric improvements in all ACR response rates assessed, DAS28-4(ESR) scores, and mean change from baseline in HAQ-DI scores. Efficacy assessed at the same time points was similar in the double-blind tofacitinib $10 \mathrm{mg}$ BID to open-label tofacitinib $10 \mathrm{mg}$ BID group and the ADA to tofacitinib $10 \mathrm{mg}$ BID group, and there was a similar pattern of increases in efficacy from the double-blind to the openlabel extension.

One of the questions of interest was whether there are clinical consequences of potential overlapping immunomodulatory effects in the switch from ADA to tofacitinib. Analysis of AEs do not support such a conclusion but, in contrast, the contribution that overlapping pharmacologic exposure to ADA and tofacitinib makes to efficacy may be more difficult to assess. Although the first efficacy assessment at 3 months is well beyond the terminal half-life of the last dose of ADA [20, 21], pharmacodynamic effects may persist beyond what might be predicted from half-life/clearance data, and coadministered MTX reduces ADA clearance [22]. Nevertheless, efficacy assessed at the same time points was similar in the tofacitinib to tofacitinib group and the
ADA to tofacitinib group, with similar numeric patterns of improvement.

\section{Conclusions}

In summary, analysis of incidence rates of AEs showed a similar pattern over time for both ADA to tofacitinib and blinded to open-label tofacitinib treatment sequences in the year before and the year after switching, and there was no clear pattern of changes in TEAEs in the 3 months before and 3 months after the switch. Switching from both double-blind ADA and tofacitinib to open-label tofacitinib resulted in numeric improvements in signs and symptoms of disease and physical function. These results indicate that a patient's treatment can be directly switched from ADA to tofacitinib $10 \mathrm{mg}$ BID, with a safety and efficacy profile similar to switching from blinded to open-label tofacitinib $10 \mathrm{mg}$ BID. This analysis did not address potential differences between the safety profiles of ADA and tofacitinib in the phase 3 study for this cohort of patients, as this comparison is more appropriate in the primary safety analysis population [10].

\section{Additional file}

Additional file 1: Table S1. Ethical review boards and study centers. (DOCX $34 \mathrm{~kb}$ )

\section{Abbreviations \\ ACR, American College of Rheumatology; ADA, adalimumab; AE, adverse event; ALC, absolute lymphocyte count; BID, twice daily; CCP, cyclic citrullinated peptide; Cl, confidence interval; CRP, C-reactive protein; DAS28-4(ESR), Disease Activity Score for 28-joint counts based on the erythrocyte sedimentation rate; DC, discontinuation; DMARD, disease-modifying anti-rheumatic drug; HAQ-DI, Health Assessment Questionnaire-Disability Index; IR, incidence rate; LDL, high- density lipoprotein; MTX, methotrexate; Q2W, every 2 weeks; RA, rheumatoid arthritis; HDL, high-density lipoprotein; SD, standard deviation; TEAE, treatment- emergent adverse event; TNFi, tumor necrosis factor inhibitor}

\section{Acknowledgements}

The authors would like to thank the patients who were involved in these studies, the A3921064 and A3921024 investigators, and the study teams including Kenneth Kwok and Clifford Aspinall. Medical writing support was provided by Gary Dever, PhD, and Annette Smith, PhD, at Complete Medical Communications and was funded by Pfizer Inc.

\section{Funding}

This study and post-hoc analysis was supported by Pfizer Inc

\section{Authors' contributions}

$M G, R V V, B W, L W, S H Z, D G, R R$, and TVJ were involved in the study design, and MG, BW, LW, SHZ, RR, and TVJ were responsible for the study conduct. $M G, B W, L W$, and RR contributed to data collection. MG, RVV, BW, LW, SHZ, $D G, P B, R R, L T$, and TVJ were involved in data analysis and interpretation. All authors critically reviewed the manuscript and approved the final draft prior to submission.

\section{Competing interests}

M Genovese has received grant/research support from and has been a consultant for Pfizer. $R$ van Vollenhoven has received grant/research support from and has been a consultant for AbbVie, BMS, GSK, MSD, Pfizer, Roche and UCB, and has been a consultant for Lilly and Vertex. B Wilkinson, L 
Wang, SH Zwillich, D Gruben, P Biswas, L Takiya, and TV Jones are employees of, and have stock or stock options in Pfizer. R Riese was an employee of Pfizer at the time of the study. All authors confirm that they have no non-financial competing interests.

\section{Author details}

'Division of Rheumatology, Stanford University, Palo Alto, CA, USA. ${ }^{2}$ Unit for Clinical Therapy Research, Inflammatory Diseases, Karolinska Institute, Stockholm, Sweden. ${ }^{3}$ Pfizer Inc, Groton, CT, USA. ${ }^{4}$ Pfizer Inc, 500 Arcola Drive, F5352, Collegeville, PA 19426, USA

\section{Received: 3 February 2016 Accepted: 10 June 2016}

Published online: 23 June 2016

\section{References}

1. Fisher MD, Watson C, Fox KM, Chen YW, Gandra SR. Dosing patterns of three tumor necrosis factor blockers among patients with rheumatoid arthritis in a large United States managed care population. Curr Med Res Opin. 2013;29(5):561-8.

2. Marchesoni A, Zaccara E, Gorla R, Bazzani C, Sarzi-Puttini P, Atzeni F, et al. TNF-alpha antagonist survival rate in a cohort of rheumatoid arthritis patients observed under conditions of standard clinical practice. Ann NY Acad Sci. 2009;1173:837-46.

3. Cohen SB, Emery P, Greenwald MW, Dougados M, Furie RA, Genovese MC, et al. Rituximab for rheumatoid arthritis refractory to anti-tumor necrosis factor therapy: Results of a multicenter, randomized, double-blind, placebocontrolled, phase III trial evaluating primary efficacy and safety at twentyfour weeks. Arthritis Rheum. 2006;54(9):2793-806.

4. Emery P, Keystone E, Tony HP, Cantagrel A, van Vollenhoven R, Sanchez A, et al. IL-6 receptor inhibition with tocilizumab improves treatment outcomes in patients with rheumatoid arthritis refractory to anti-tumour necrosis factor biologicals: results from a 24-week multicentre randomised placebo-controlled trial. Ann Rheum Dis. 2008;67(11):1516-23.

5. Genovese MC, Becker JC, Schiff M, Luggen M, Sherrer Y, Kremer J, et al. Abatacept for rheumatoid arthritis refractory to tumor necrosis factor alpha inhibition. N Engl J Med. 2005;353(11):1114-23.

6. Meyer DM, Jesson MI, Li X, Elrick MM, Funckes-Shippy CL, Warner JD, et al. Anti-inflammatory activity and neutrophil reductions mediated by the JAK1/JAK3 inhibitor, CP-690,550, in rat adjuvant-induced arthritis. J Inflamm (Lond). 2010;7:41.

7. Burmester GR, Blanco R, Charles-Schoeman C, Wollenhaupt J, Zerbini C, Benda B, et al. Tofacitinib (CP-690,550) in combination with methotrexate in patients with active rheumatoid arthritis with an inadequate response to tumour necrosis factor inhibitors: a randomised phase 3 trial. Lancet. 2013;381(9865):451-60.

8. Fleischmann R, Kremer J, Cush J, Schulze-Koops H, Connell CA, Bradley JD, et al. Placebo-controlled trial of tofacitinib monotherapy in rheumatoid arthritis. N Engl J Med. 2012;367(6):495-507.

9. van der Heijde D, Tanaka Y, Fleischmann R, Keystone E, Kremer J, Zerbini C, et al. Tofacitinib (CP-690,550) in patients with rheumatoid arthritis receiving methotrexate: twelve-month data from a twenty-four-month phase III randomized radiographic study. Arthritis Rheum. 2013;65(3):559-70.

10. van Vollenhoven RF, Fleischmann R, Cohen S, Lee EB, García Meijide JA, Wagner $\mathrm{S}$, et al. Tofacitinib or adalimumab versus placebo in rheumatoid arthritis. N Engl J Med. 2012;367(6):508-19.

11. Kremer J, Li ZG, Hall S, Fleischmann R, Genovese M, Martin-Mola E, et al. Tofacitinib in combination with nonbiologic disease-modifying antirheumatic drugs in patients with active rheumatoid arthritis: a randomized trial. Ann Intern Med. 2013;159(4):253-61.

12. Lee EB, Fleischmann R, Hall S, Wilkinson B, Bradley J, Gruben D, et al. Tofacitinib versus methotrexate in rheumatoid arthritis. N Engl J Med. 2014;370(25):2377-86.

13. Wollenhaupt J, Silverfield J, Lee EB, Curtis JR, Wood SP, Soma K, et al. Safety and efficacy of tofacitinib, an oral Janus kinase Inhibitor, for the treatment of rheumatoid arthritis in open-label, longterm extension studies. J Rheumatol. 2014;41(5):837-52.

14. Arnett FC, Edworthy SM, Bloch DA, McShane DJ, Fries JF, Cooper NS, et al. The American Rheumatism Association 1987 revised criteria for the classification of rheumatoid arthritis. Arthritis Rheum. 1988;31(3):315-24.

15. Fleischmann R, Cutolo M, Genovese MC, Lee EB, Kanik KS, Sadis S, et al. Phase Ilb dose-ranging study of the oral JAK inhibitor tofacitinib
(CP-690,550) or adalimumab monotherapy versus placebo in patients with active rheumatoid arthritis with an inadequate response to diseasemodifying antirheumatic drugs. Arthritis Rheum. 2012;64(3):617-29.

16. Kremer JM, Bloom BJ, Breedveld FC, Coombs JH, Fletcher MP, Gruben D, et al. The safety and efficacy of a JAK inhibitor in patients with active rheumatoid arthritis: Results of a double-blind, placebo-controlled phase lla trial of three dosage levels of CP-690,550 versus placebo. Arthritis Rheum. 2009;60(7):1895-905.

17. Kremer JM, Cohen S, Wilkinson BE, Connell CA, French JL, Gomez-Reino J, et al. A phase Ilb dose-ranging study of the oral JAK inhibitor tofacitinib (CP-690,550) versus placebo in combination with background methotrexate in patients with active rheumatoid arthritis and an inadequate response to methotrexate alone. Arthritis Rheum. 2012;64(4):970-81.

18. Tanaka Y, Suzuki M, Nakamura H, Toyoizumi S, Zwillich SH, Investigators TS. Phase II study of tofacitinib (CP-690,550) combined with methotrexate in patients with rheumatoid arthritis and an inadequate response to methotrexate. Arthritis Care Res (Hoboken). 2011;63(8):1150-8.

19. Tanaka Y, Takeuchi T, Yamanaka H, Nakamura H, Toyoizumi S, Zwillich S. Efficacy and safety of tofacitinib as monotherapy in Japanese patients with active rheumatoid arthritis: a 12-week, randomized, phase 2 study. Mod Rheumatol. 2015;25(4):514-21.

20. den Broeder A, van de Putte L, Rau R, Schattenkirchner M, van Riel P, Sander $\mathrm{O}$, et al. A single dose, placebo controlled study of the fully human anti-tumor necrosis factor-alpha antibody adalimumab (D2E7) in patients with rheumatoid arthritis. J Rheumatol. 2002;29(11):2288-98.

21. Weisman MH, Moreland LW, Furst DE, Weinblatt ME, Keystone EC, Paulus HE, et al. Efficacy, pharmacokinetic, and safety assessment of adalimumab, a fully human anti-tumor necrosis factor-alpha monoclonal antibody, in adults with rheumatoid arthritis receiving concomitant methotrexate: a pilot study. Clin Ther. 2003;25(6):1700-21.

22. AbbVie Inc. Humira prescribing information. 2015. www.rxabbvie.com/pdf/ humira.pdf. Accessed 1 Dec 2015.

\section{Submit your next manuscript to BioMed Central and we will help you at every step:}

- We accept pre-submission inquiries

- Our selector tool helps you to find the most relevant journal

- We provide round the clock customer support

- Convenient online submission

- Thorough peer review

- Inclusion in PubMed and all major indexing services

- Maximum visibility for your research

Submit your manuscript at www.biomedcentral.com/submit 